\title{
Controlled Synthesis and Understanding of Growth Mechanism - Parameters for Atmospheric Pressure Hydrothermal Synthesis of Ultrathin Secondary ZnO Nanowires
}

\author{
Mingzhi Jiao ${ }^{1}$, Duc Hoa Nguyen ${ }^{2}$, Van Duy Nguyen ${ }^{2}$, Van Hieu Nguyen ${ }^{2}$, \\ Klas Hjort ${ }^{1}$ and Hugo Nguyen ${ }^{1^{*}}$ \\ ${ }^{1}$ Department of Engineering Sciences, Division of Microsystem Technology, \\ Uppsala University, Sweden. \\ ${ }^{2}$ International Training Institute for Materials Science (ITIMS), \\ Hanoi University of Science and Technology, Hanoi, Vietnam.
}

\begin{abstract}
Authors' contributions
This work was carried out in collaboration between all authors. Authors MJ and HN designed the study, performed the experiments, wrote the protocol and wrote the first draft of the manuscript. Authors MJ, DHN, VDN and HN managed the literature searches, performed the spectroscopy and microscopy analysis. All authors read and approved the final manuscript.

Article Information

DOI: 10.9734/JSRR/2016/22427

(1) Ming-Jyh Chern, Department of Mechanical Engineering, National Taiwan University of Science and Technology, Taiwan.

Reviewers:

(1) Subramaniam Jahanadan, Kolej Matrikulasi Labuan (KML), Malaysia. (2) Yong Gan, California State Polytechnic University, Pomona, USA. (3) Enhua Wang, Tsinghua University, China. Complete Peer review History: http://sciencedomain.org/review-history/12229
\end{abstract}

Original Research Article

Received $1^{\text {st }}$ October 2015

Accepted $30^{\text {th }}$ October 2015

Published $10^{\text {th }}$ November 2015

\section{ABSTRACT}

Synthesis of ultrathin $\mathrm{ZnO}$ nanowires gains great attention from research community because of their large potential in applications involving optoelectronics and sensors. In this study, a lowpressure and low-temperature hydrothermal synthesis of ultrathin $\mathrm{ZnO}$ nanowires is studied to understand the growth mechanisms better. To achieve this aim, an about $10 \mathrm{~nm}$ thin $\mathrm{Zn}$ seed layer was sputter-deposited on a silicon (100) wafer for the hydrothermal growth of $\mathrm{ZnO}$ nanowires in an equimolar aqueous solution of $\mathrm{Zn}\left(\mathrm{NO}_{3}\right)_{2}$ and hexamethylenetetramine. X-ray diffraction analysis 
confirmed that the $\mathrm{Zn}$ layer was self-oxidized into $\mathrm{ZnO}$ in air soon after deposition and then functioned as the seed for the preferred growth of c-oriented $\mathrm{ZnO}$ nanorods. Different growth conditions were investigated to identify how concentration, temperature, and time influence the final morphology of the synthesized $\mathrm{ZnO}$ nanostructures. It was found that under the atmospheric pressure, concentration and temperature have to be higher than $0.0025 \mathrm{M}$ and $50^{\circ} \mathrm{C}$, respectively, for the $\mathrm{ZnO}$ nanorods to nucleate and grow densely. Low concentration gives sparse and randomly oriented nanorods, whereas high concentration gives dense and vertical nanorods. Ultrathin ZnO secondary nanowires with an average diameter of less than $20 \mathrm{~nm}$ were successfully synthesized in a solution with concentration of $0.005 \mathrm{M}$ at $90^{\circ} \mathrm{C}$ for about $16 \mathrm{~h}$. By analyzing the scanning electron microscopy images of the $\mathrm{ZnO}$ nanostructures obtained at different growth conditions, a mechanism is proposed for the growth of the ultrathin secondary $\mathrm{ZnO}$ nanowires. This finding provides a cost-effective and straightforward pathway to prepare ultrathin ZnO nanowires.

Keywords: ZnO nanowires; growth parameters; growth mechanism.

\section{INTRODUCTION}

Materials based on $\mathrm{ZnO}$ nanowire (NW) is one of the most investigated nanomaterials for various sensing applications because of its exceptional physicochemical properties and ease of synthesis [1-3]. ZnO NWs with a diameter of about $20 \mathrm{~nm}$ have been a topic of interest for gas sensors for a while [4,5], and the diameter has been reduced to enhance gas sensitivity [6].

Extensive work has been dedicated to the synthesis of $\mathrm{ZnO} \mathrm{NWs}$ employing generally two methods: Vapour phase synthesis, which is also called chemical vapour deposition (CVD), and liquid phase synthesis [7]. CVD has been the most widely used method for growing highquality $\mathrm{ZnO}$ NWs [8]. In CVD, the vapour-liquidsolid (VLS) mechanism is generally responsible for the growth of NWs via vapour phase synthesis, and the diameter of the NWs can be controlled by the size of the catalyst nanodots $[9,10]$. However, the substrate has to endure a high temperature, typically $900-950^{\circ} \mathrm{C}$, in an oxidizing environment $[11,12]$. Thus, CVD is not a suitable method for flexible plastic substrates, and for other electrode material than refractive and noble material, such as $\mathrm{Pt}$, that may have to be deposited prior to CVD in different sensor applications. On the other hand, the chemical synthesis pathways that use the liquid phase as a source for growing of $\mathrm{ZnO} \mathrm{NWs}$ offer many advantages, for instance, no need for expensive equipment and noble metal catalyst [13]. The most well-known liquid phase synthesis of $\mathrm{ZnO}$ is the so-called hexamethylenetetramine (HMTA) hydrothermal method [14]. This method is widely used in the synthesis of nanostructured $\mathrm{ZnO}$ material such as nanorods (NRs) and NWs. Equimolar aqueous solution of $\mathrm{Zn}\left(\mathrm{NO}_{3}\right)_{2}$ and HMTA has been used mostly to grow ZnO NRs and NWs on Si and glass substrates. A $\mathrm{ZnO}$ seed layer is needed to initiate the uniform growth of oriented NWs [13-15]. The diameter of ZnO NRs and NWs could be controlled by the grain size of the thin seed layer [13-16]. A thin and fine-grained seed layer is expected to yield small diameter. For instance, a $10 \mathrm{~nm}$ thick layer of textured $\mathrm{ZnO}$ nanocrystals deposited by decomposing zinc acetate at $200-350^{\circ} \mathrm{C}$ has been used for successful growth of vertical, short $\mathrm{ZnO}$ NWs with diameters of $15-65 \mathrm{~nm}$ [17]. Atomic layer deposition (ALD) and pulsed laser deposition (PLD) have also been used to deposit an uniform $\mathrm{ZnO}$ seed layer to grow $\mathrm{ZnO} \mathrm{NRs}$ and nanotubes (NTs) on different substrates, where ZnO NTs with diameters of 20-60 nm have been successfully produced [13-18]. ALD and PLD methods can provide excellent and very thin $\mathrm{ZnO}$ seed layers for growing $\mathrm{ZnO} N W s$, but these methods are expensive. Some researchers have reported the use of autoclaving to achieve higher temperatures for the hydrothermal method, and NRs and NWs with smaller diameters [19]. Preparation of $\mathrm{ZnO}$ nanomaterials at lower costs can be made via sputter deposition and spray pyrolysis [20]. Generally, ZnO NRs grown via the hydrothermal routes at optimum condition are typically larger than $20 \mathrm{~nm}$ in diameter [21-24], and NRs with diameters of larger than $100 \mathrm{~nm}$ are easy to achieve. However, to our knowledge, there are no conclusive investigations of critical parameters, such as concentration of precursors, temperature of the solution, and time for nucleation and growth of $\mathrm{ZnO} \mathrm{NRs}$ and NWs. Understanding the growth mechanism is very important for the control and prediction of the morphology of the synthesized ZnO NWs [25]. Preparing $\mathrm{ZnO}$ NWs with diameters of less than $20 \mathrm{~nm}$ with the hydrothermal method is still challenging, especially at temperatures below the boiling point of the solution and at atmospheric 
pressure, so that even the autoclave, which is the most expensive piece of equipment in this method, can be eliminated, thereby enabling a very simple and scalable production of $\mathrm{ZnO}$ NWs.

This study aims to determine the best and most affordable pathway for the on-site hydrothermal growth of uniformly long $\mathrm{ZnO} \mathrm{NWs}$ with diameters of less than $20 \mathrm{~nm}$. It includes a facile sputter deposition of a thin seed layer of $\mathrm{Zn}$, and synthesis of $\mathrm{ZnO} N W s$ in solution at a temperature below its boiling point and at atmospheric pressure. We focus on controlling the precursor concentrations, growth temperatures, and growth time to obtain ultrathin $\mathrm{ZnO} \mathrm{NWs}$ for gas-sensing applications, and on understanding of growth mechanism of these NWs. To our knowledge, this is the first systematic investigation of these parameters for growth of ultrathin $\mathrm{ZnO} N W s$ with the HTMA hydrothermal method.

\section{EXPERIMENTAL DETAILS}

\subsection{Materials}

$\mathrm{Zn}\left(\mathrm{NO}_{3}\right)_{2} \cdot 6 \mathrm{H}_{2} \mathrm{O}$ and HMTA powder (both with purity $\geq 99.0 \%$, Sigma-Aldrich, Sweden), Zn target (purity 99.99\%, MatecK, Germany), and standard 4-inch p-type silicon wafers (100) were used in the experiments.

\subsection{Deposition of Seed Layer}

The seed layer was created by sputtering from $\mathrm{Zn}$ target. This method is straightforward and cost-effective because the price of the $\mathrm{Zn}$ target is usually one-third that of $\mathrm{ZnO}$ target with similar purity. $\mathrm{Zn}$ was expected to self-oxidize to $\mathrm{ZnO}$ and function as the seed layer for the hydrothermal growth of $\mathrm{ZnO} \mathrm{NWs}$. A sputtering system (K675XD Turbo Sputter Coater, EMITECH) was used to sputter-deposit an $8-10$ $\mathrm{nm}$ thin layer of $\mathrm{Zn}$ on a Si wafer. The sputtering parameters were: base pressure of $1.33 \times 10^{-6}$ mbar, Ar gas atmosphere of $7 \times 10^{-3}$ mbar, current of $50 \mathrm{~mA}$, and tooling factor of 9.6. The thickness of the deposited and oxidized $\mathrm{Zn}$ layer was measured using a profilometer (Dektak 150 Stylus Profilometry).

\subsection{Hydrothermal Growth of ZnO NWs}

$\mathrm{ZnO} \mathrm{NW}$ growth was carried out in an equimolar aqueous solution of $\mathrm{Zn}\left(\mathrm{NO}_{3}\right)_{2}$ and HMTA. Small pieces of the Zn-sputtered silicon substrate were mounted to a Teflon stick to orient the seed layer face-down in a glass bottle with the precursor solution. The bottle was placed in an oven at a stable operation temperature for the growth of NWs. To prevent quick evaporation of the solution and to keep the atmospheric pressure, an aluminium foil was used to cover the bottle. Different experiment series were performed to investigate the effect of growth parameters, i.e., temperature, time, and concentration of the solution on the morphology of the synthesized nanomaterial, with emphasis on synthesizing NWs with diameters of less than $20 \mathrm{~nm}$. After the synthesis, the samples were submerged in deionized water three times for about 5 min each. The samples were placed in an oven at $75^{\circ} \mathrm{C}$ for about $10 \mathrm{~h}$ to dry and stabilize the synthesized NWs.

\subsection{Materials Characterization}

The morphologies of both the $\mathrm{Zn}$ layer (before hydrothermal synthesis) and the synthesized ZnO NWs were examined using a field emission scanning electron microscope (LEO 1550, Carl Zeiss SMT, Germany) at an acceleration voltage of $3 \mathrm{keV}$. Atomic force microscopy (AFM) image was taken using PSIA XE150 AFM (Suwon, Korea) in non-contact mode. X-ray diffraction (XRD, Parallel Beam Geometry with X-ray mirrors, SIEMENS D5000, Germany) measurement was performed to analyze the crystal orientation of the $\mathrm{Zn}$ seed layer and the synthesized $\mathrm{ZnO} N W s$. Grazing incidence XRD (grazing incidence angle of $0.3^{\circ}$ ) was set to lower the intensity of the diffraction signals from the silicon substrate underneath.

\section{RESULTS AND DISCUSSION}

The morphology and quality of the deposited $\mathrm{Zn}$ seed layer as characterized by SEM, and the AFM images are shown in Fig. 1. Fig. 1A reveals that after being oxidized in ambient air, the sputter-deposited $\mathrm{Zn}$ layer is very dense and uniform. As confirmed by the profilometric measurement, the deposited layer has a very small thickness of less than $10 \mathrm{~nm}$. The thin film is composed of very tiny nanocrystals in an amorphous matrix. Based on the SEM and AFM measurements, the crystal size is about $5 \mathrm{~nm}$, and the surface roughness is less than $1.2 \mathrm{~nm}$, Fig. 1B. The homogenous deposition of the $\mathrm{Zn}$ layer by sputtering is advantageous for the predefined sites of hydrothermally grown $\mathrm{ZnO} \mathrm{NWs}$. 

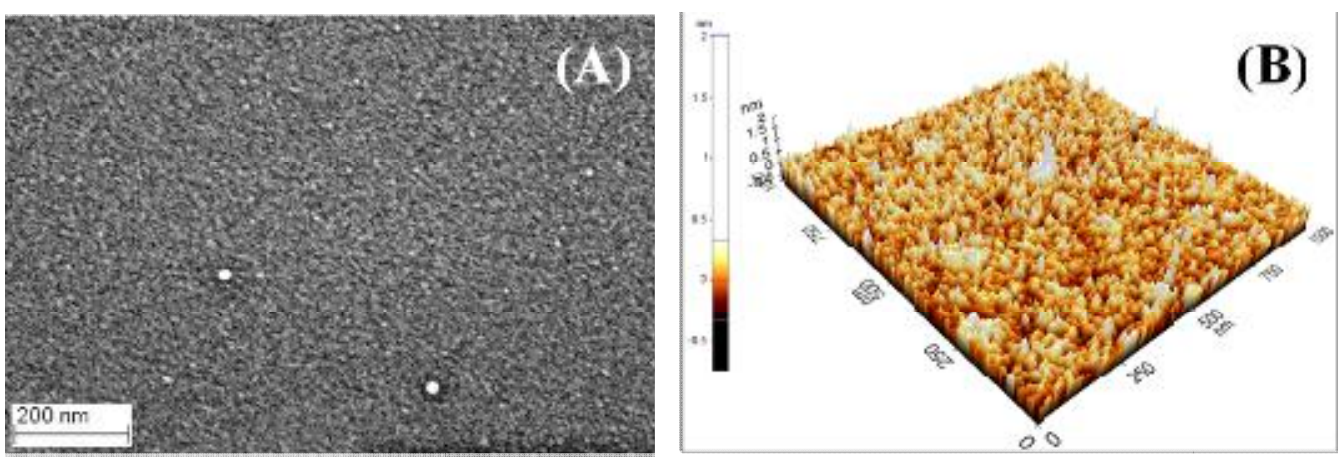

Fig. 1. (A) SEM and (B) AFM images of the sputter-deposited Zn seed layer

The results from XRD investigations of crystal type and orientation of the sputtered $\mathrm{Zn}$ layer and the hydrothermally grown $\mathrm{ZnO} \mathrm{NWs}$ are presented in Fig. 2. The XRD pattern of the deposited Zn layer, Fig. 2(A), shows a peak at $34.3^{\circ}$ belonging to the (002) plane of the hexagonal ZnO crystal (JCPDS, 89-1397). The narrow peak beside this refers to the (211) plane of the silicon substrate, which confirms that the chemically active $\mathrm{Zn}$ layer was naturally selfoxidized to $\mathrm{ZnO}$ as it was taken out from the sputter chamber and exposed to $\mathrm{O}_{2}$ in air. The crystal size calculated from the XRD data by using the (002) peak, and Scherrer equation, confirmed that the average size of the $\mathrm{ZnO}$ nanocrystal is about $5 \mathrm{~nm}$. The XRD pattern of the hydrothermally grown $\mathrm{ZnO} \mathrm{NWs}$, Fig. 2(B), shows typical peaks of the hexagonal $\mathrm{ZnO}$ crystal (JCPDS, 89-1397) with a preferred growth direction along the c-axis. This result is consistent with other reports on hydrothermally synthesized $\mathrm{ZnO}$ NWs. The preferred growth direction along the c-axis is due to the lower energy required for NW growth at the hydrothermal condition.

\subsection{Effect of Solution Concentration}

The morphology and diameter of the $\mathrm{ZnO}$ nanostructures prepared with the HTMA hydrothermal method are very much dependent on the amount of precursor available in the solution. Fig. 3 shows the SEM images of the $\mathrm{ZnO}$ nanostructures grown in solutions with concentrations of $0.125,0.025,0.005$ and 0.001 $\mathrm{M}$ at $80^{\circ} \mathrm{C}$ for $6 \mathrm{~h}$. At a very high concentration, no NRs or NWs can be obtained, Fig. 3(A). Instead, the resulting material seems to be a thick layer of $\mathrm{ZnO}$ with some aggregated $\mathrm{ZnO}$ debris. However, at lower concentrations, the obtained material consists of hexagonal NRs but not NWs, which suggests that the growth mechanism did not favour the forming of NW morphology under these conditions, Figs. 3(B-D). As revealed by the SEM images, the average diameter of the $\mathrm{ZnO}$ NRs decreased with concentration. However, the diameter of the $\mathrm{ZnO}$ NRs ranged from 50 to about $130 \mathrm{~nm}$. Figs. 3(B-C) show that the concentration of precursor was sufficiently high to lead to dense growth, and, thus, only the vertical NRs could survive, whilst Fig. 3(D) shows that a very low concentration of precursor leads to a coarse nucleation of the seeds, resulting in randomly oriented NRs. However, the diameter of the obtained $\mathrm{ZnO} \mathrm{NRs}$ in this experiment is still too large compared with the size of the seed grains, which are, as mentioned above, about $5 \mathrm{~nm}$ in diameter. This result indicates that the diameter of $\mathrm{ZnO}$ NRs was not determined only by the size of the single seeds but also by the amount of the precursor available in the solution. A possible explanation is that a NR that nucleates from a very small seed can grow dominantly to a certain diameter and cover the other seeds within its footprint. However, the actual conditions, i.e. temperature and pressure, are not seemed to be favourable, or high enough, for the very thin NWs to grow directly from the seeds, although the concentration of precursor in the solution is very low.

\subsection{Effect of Growth Temperature}

To investigate the effect of growth temperature on the morphology of the ZnO NRs, we selected a solution concentration of $0.005 \mathrm{M}$ from the former experiment for the second series of experiment, but varied the temperature from 40 to $100^{\circ} \mathrm{C}$. The growth time was extended from 6 to $10 \mathrm{~h}$ because the hydrothermal reaction was now carried out in a wide range of temperatures. Fig. 4(A) shows that the morphology of the $\mathrm{ZnO}$ at $40^{\circ} \mathrm{C}$ looks like the seed layer, and no NRs 
were found on the substrate. This result is possibly due to the fact that the low thermal energy provided in the hydrothermal process was not sufficient for the decomposition of HTMA and the nucleation of $\mathrm{ZnO}$ for the NR growth, Eq. (1) to (6), [10]. At $50^{\circ} \mathrm{C}$, Fig. $4 \mathrm{~B}$, short and sparsely nucleated NRs could be observed. At $60^{\circ} \mathrm{C}$, Fig. 4C, roughly the same result was obtained as that from the previous experiment at $80^{\circ} \mathrm{C}$ with the same concentration of $0.005 \mathrm{M}$, Fig. 3C. The NRs grown in the solution at $100^{\circ} \mathrm{C}$ are also more or less of the same morphology, except that the top parts of the rods started to grow smaller and formed pointed tips that look like a transition to secondary NWs, Fig. 4D. This interesting result suggests that the concentration of the solution decreased due to a higher rate of growth [26] and prolongation of time at a high temperature $\left(\sim 100^{\circ} \mathrm{C}\right)$. After $10 \mathrm{~h}$, the concentration of the solution was probably not enough to maintain the growth of the homogenous NRs with constant diameter.
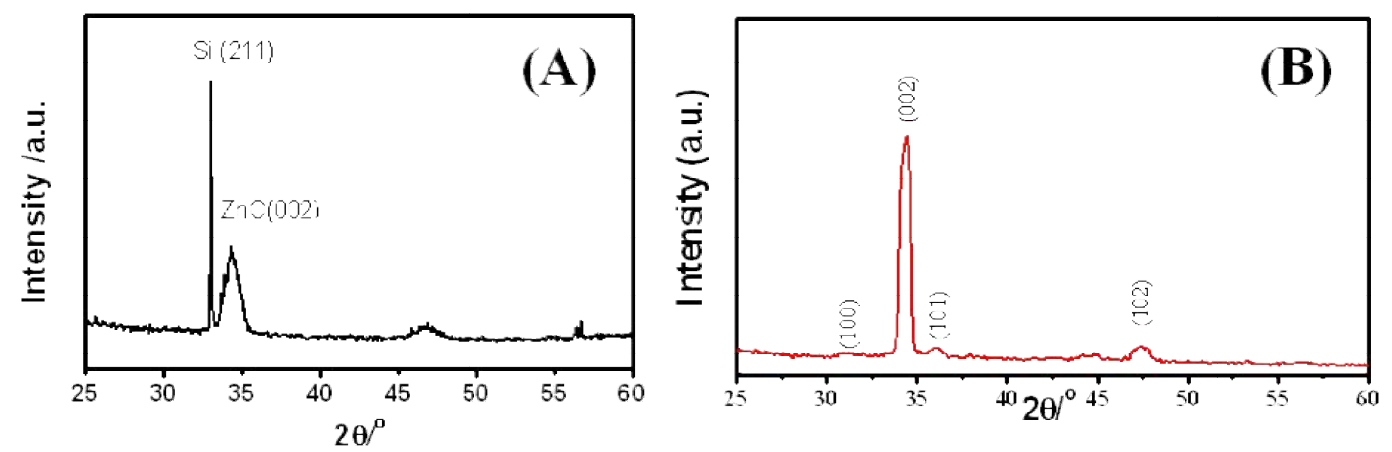

Fig. 2. XRD patterns of (A) the sputter-deposited Zn seed layer and (B) hydrothermally grown $\mathrm{ZnO}$ nanostructures (grown at $80^{\circ} \mathrm{C}$ for $6 \mathrm{~h}$ in solution with concentration of $0.125 \mathrm{M}$ )
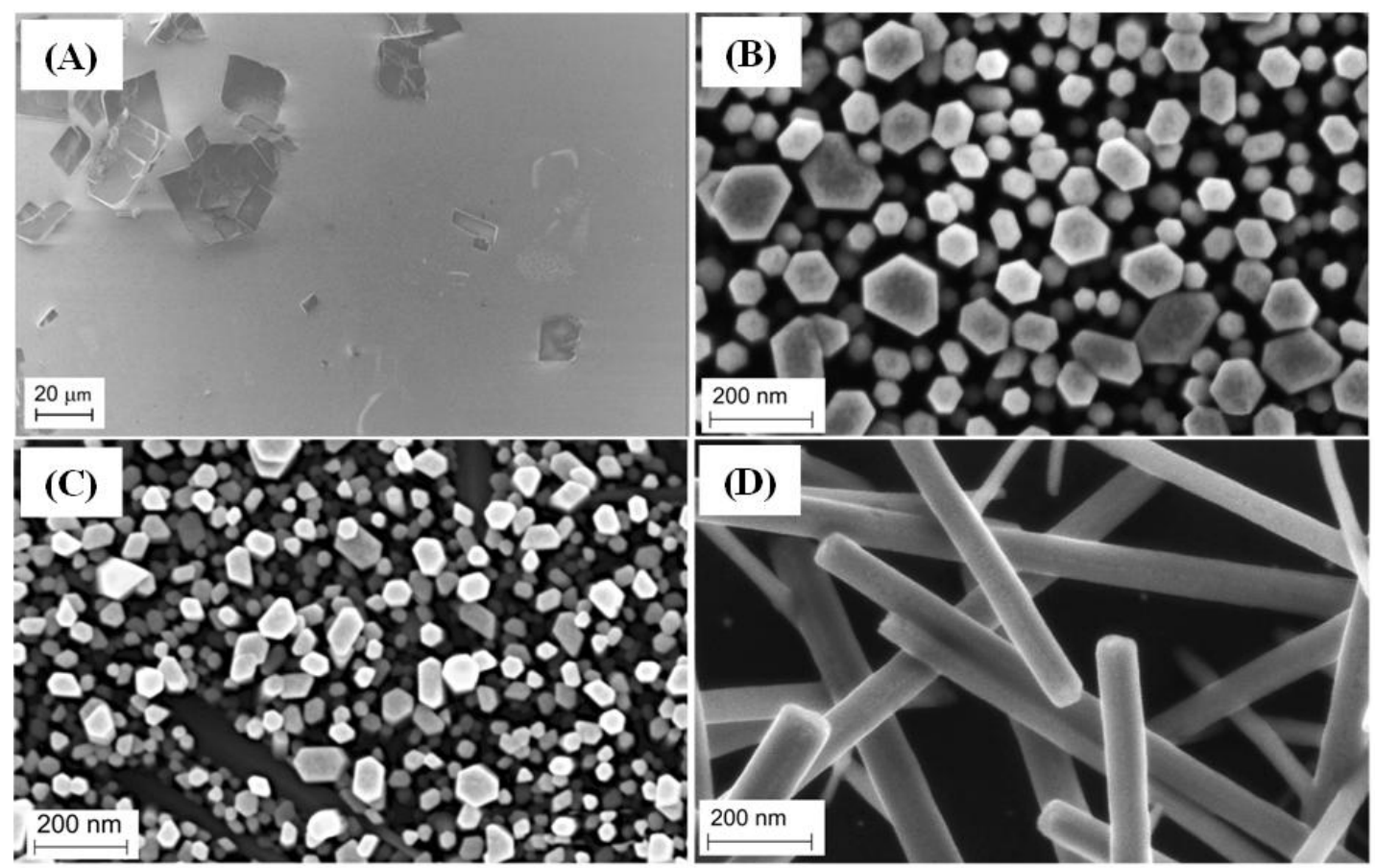

Fig. 3. SEM images of $\mathrm{ZnO}$ nanostructures grown at $80^{\circ} \mathrm{C}$ for $6 \mathrm{~h}$ in different solution concentrations: (A) $0.125 \mathrm{M}$; (B) $0.025 \mathrm{M}$; (C) $0.005 \mathrm{M}$; and (D) $0.001 \mathrm{M}$. Note that panel (A) has a scale of two orders larger than that of the other for observability 

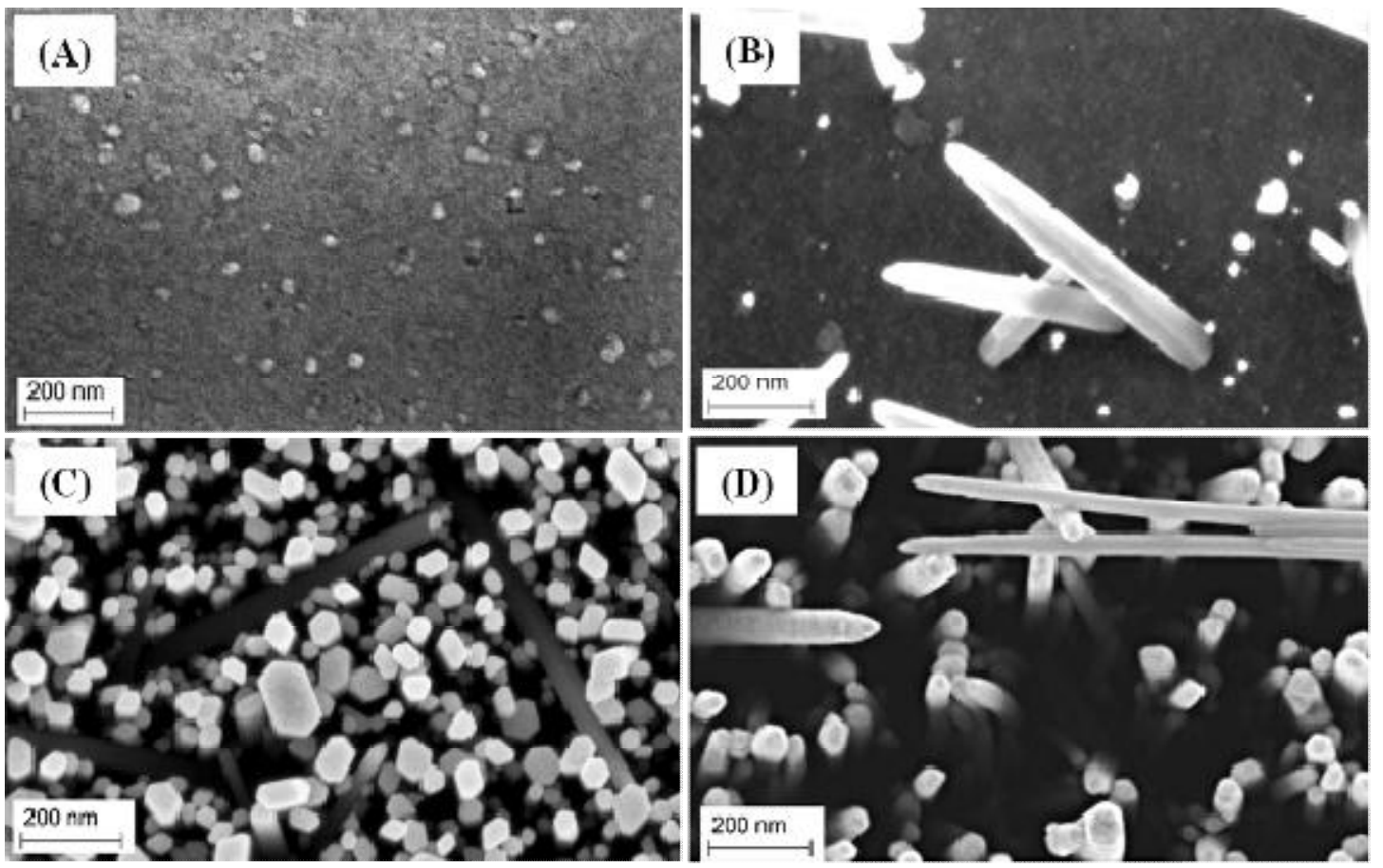

Fig. 4. SEM images of $\mathrm{ZnO}$ nanostructures grown in $0.005 \mathrm{M}$ solution concentration at various temperatures for $10 \mathrm{~h}$ : (A) $40^{\circ} \mathrm{C}$

\subsection{Effect of Growth Time}

Based on the results presented above, a new experiment series was conducted with different solution concentrations at a moderately high temperature and a longer growth time to obtain ultrathin $\mathrm{ZnO} \mathrm{NWs}$. The results showed that secondary NWs are difficult to obtain at $80^{\circ} \mathrm{C}$ and at solution concentrations of 0.0025 and $0.001 \mathrm{M}$. At a temperature of about $90^{\circ} \mathrm{C}$, however, NWs with a diameter of $20 \mathrm{~nm}$ can be obtained at the same low solution concentration of $0.0025 \mathrm{M}$, Fig. 5A, or a higher concentration of $0.005 \mathrm{M}$, Fig. 5B. This indicates that high growth temperature and prolongation of growth time, here up to $16 \mathrm{~h}$ or more, play an important role in growing ultrathin $\mathrm{ZnO}$ NWs.

To obtain further insight into the growth mechanism of the ultrathin NWs, another series of experiment was conducted using concentration of $0.005 \mathrm{M}$ at the same temperature of $90{ }^{\circ} \mathrm{C}$, but with growth times of 2 , 9 , and $36 \mathrm{~h}$. The results showed that growth for only $2 \mathrm{~h}$ produced only a dense layer of NRs. However, after $9 \mathrm{~h}$, the NRs became longer and appeared more porous and sharp at the tips, similar to the result shown in Fig. 4(D). The sharp tips of the NRs are very important for the growth of ultrathin $\mathrm{ZnO} \mathrm{NWs}$, as demonstrated in Fig. 5C, where ultrathin $\mathrm{ZnO} \mathrm{NWs}$ were grown from the sharp tips of the NRs when the time was increased to $36 \mathrm{~h}$. Hence, a longer growth time is important for the growth of ultrathin secondary $\mathrm{ZnO} N W s$. This phenomenon may be explained by the reduction of the $\mathrm{Zn}^{2+} / \mathrm{OH}^{-}$ratio with time, which normally favours the formation of thinner NWs [25].

To make use of the results obtained from the large series of experiments, an attempt to grow a gas sensor demonstrator was made. The sensor consisted of electrodes deposited on a glass substrate, similar to the design reported in [12]. A thin seed layer of $\mathrm{Zn}$ was sputter-deposited and patterned by lift-off on and between the electrodes to form an array of circular islands with diameter of $5 \mu \mathrm{m}$ at a distance of $5 \mu \mathrm{m}$ from each other. Ultrathin secondary NWs were then successfully grown on the predefined seed islands in a solution and under the same growth conditions as in the experiment shown in Fig. 5(C). As seen in Fig. 5(D), the NWs of $\mathrm{ZnO}$ are well developed and formed NW-NW junctions between the islands. A gas sensor with this design, but with CVD synthesized ZnO NWs, has shown a high sensitivity to $\mathrm{NO}_{2}$, as reported in [12]. 

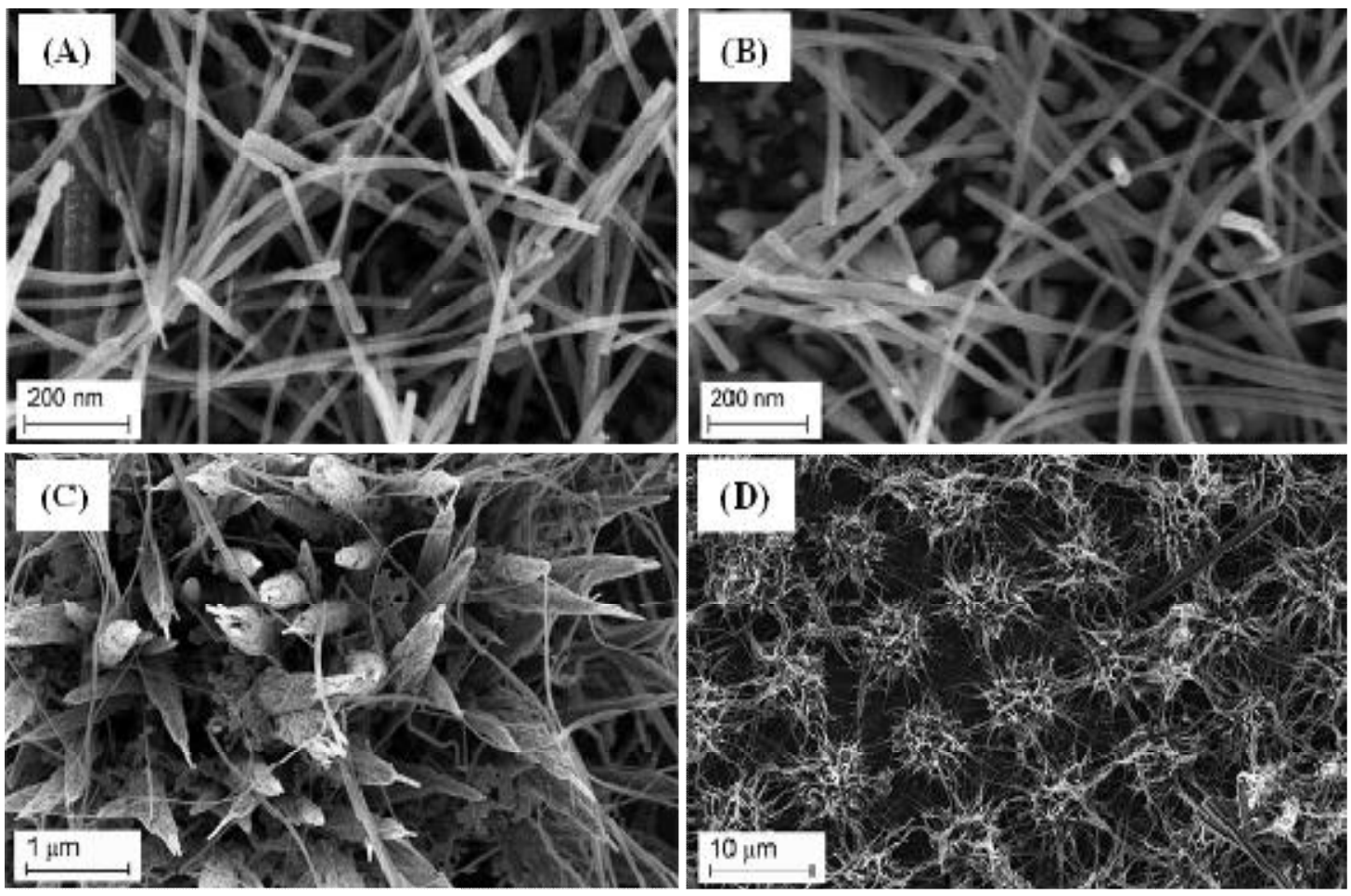

Fig. 5. SEM images of nanostructures grown at $90^{\circ} \mathrm{C}$ in concentration of (A) $0.0025 \mathrm{M}$ for $16 \mathrm{~h}$; (B) $0.005 \mathrm{M}$ for $20 \mathrm{~h}$; (C) and (D) $0.005 \mathrm{M}$ for $36 \mathrm{~h}$. Note that panel (C) and (D) has different scales from that of $(A)$ and $(B)$ for observability

\subsection{Growth Mechanism of Ultrathin ZnO NWs}

From the observation above, the concentration of the solution is a very important parameter to initiate the growth of ultrathin secondary $\mathrm{ZnO}$ NWs. As shown in this study, ultrathin ZnO NWs can be grown in a critical concentration and with the help of sharp tips of the NRs. Thus, a growth mechanism for the ultrathin secondary ZnO NWs including a three-step process, as shown in Fig. 6 , is proposed. The first step (i) is the formation of a dense layer of $\mathrm{ZnO} N R s$ on a thin seed layer of the same material of $\mathrm{ZnO}$, Fig. 6(A) and 6(B), followed by the second step (ii) of formation of sharp tips and nucleation of secondary seeds, Figs. $6 \mathrm{~B}$ and $6 \mathrm{C}$, and then by (iii) the growth of ultrathin secondary NWs from the tips of the $\mathrm{ZnO}$ NRs, Figs. 6C and 6D.

The proposed growth mechanism can be explained with the help of the following chemical reactions that occur in aqueous solution during the hydrothermal growth [10].

$$
\begin{aligned}
& \mathrm{Zn}\left(\mathrm{NO}_{3}\right)_{2} \leftrightarrow \mathrm{Zn}^{2+}+2 \mathrm{NO}_{3}^{-} \\
& \left(\mathrm{CH}_{2}\right)_{6} \mathrm{~N}_{4}+6 \mathrm{H}_{2} \mathrm{O} \leftrightarrow 6 \mathrm{CH}_{2} \mathrm{O}+4 \mathrm{NH}_{3}
\end{aligned}
$$

$$
\begin{aligned}
& \mathrm{NH}_{3}+\mathrm{H}_{2} \mathrm{O} \leftrightarrow \mathrm{NH}^{+}+\mathrm{OH}^{-} \\
& \mathrm{Zn}^{2+}+4 \mathrm{NH}_{3} \leftrightarrow\left[\mathrm{Zn}\left(\mathrm{NH}_{3}\right)_{4}\right]^{2+} \\
& \mathrm{Zn}^{2+}+2 \mathrm{OH}^{-} \leftrightarrow \mathrm{Zn}(\mathrm{OH})_{2} \\
& \mathrm{Zn}(\mathrm{OH})_{2} \leftrightarrow \mathrm{ZnO}+\mathrm{H}_{2} \mathrm{O}
\end{aligned}
$$

The growth of ZnO NRs and NWs depends on the rate of these reactions. Initially, the concentration of $\mathrm{Zn}^{2+}$ in the solution is so high that reactions (1)-(6) occur easily, given that the solution temperature is high enough for HTMA to decompose, i.e, above $50^{\circ} \mathrm{C}$, as found in this study. Thus, the first step occurs for the growth of dense layer $\mathrm{ZnO}$ NRs. With prolongation of growth time, the length of the ZnO NRs increases, and the concentration of the precursor in the solution decreases. At a critical growth time of $t_{c}$, the remnant precursor approaches the critical concentration $\mathrm{C}_{c}$, which is not sufficient for the growth of constant-diameter NRs. Therefore, the tips of NRs become sharper, and the nucleation of ultrathin secondary seeds then occurs, as in the second step. In the third step, ultrathin $\mathrm{ZnO} \mathrm{NWs}$ grow from the secondary seeds to form ultrathin and long $\mathrm{ZnO} N W s$ until the precursor is used up. 
(A)

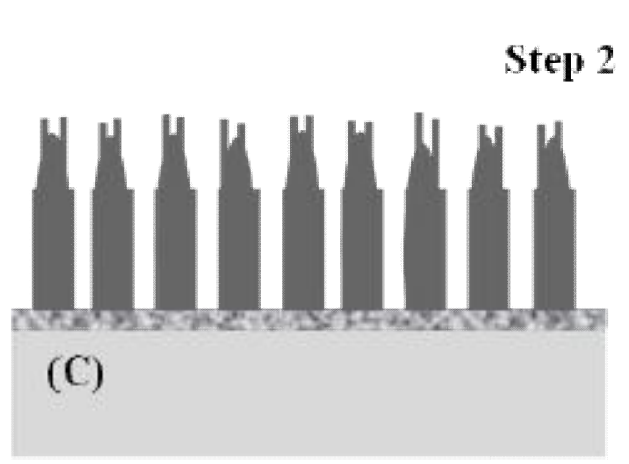

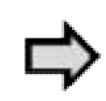

Step 1

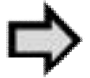

Step 3
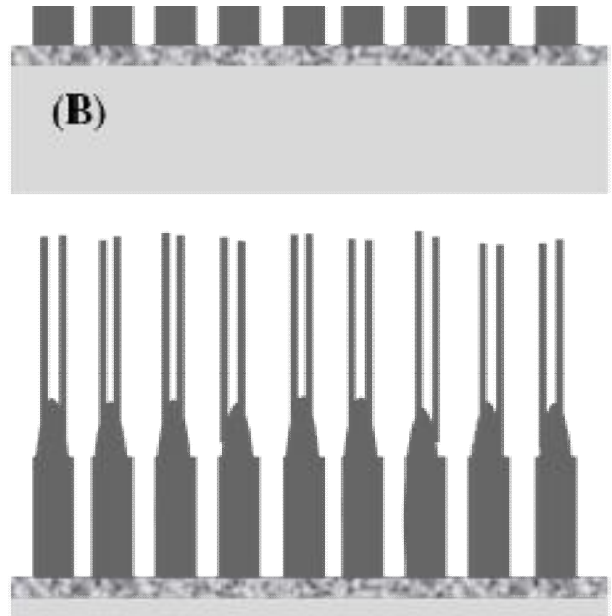

(D)

Fig. 6. Proposed mechanism for the growth of ultrathin $\mathrm{ZnO}$ NWs from formation of big $\mathrm{ZnO}$ NRs from seed layer to nucleation and growth of secondary ultrathin ZnO NWs from the tips of the NRs

\section{CONCLUSION}

Hydrothermal synthesis can be used for low-cost studies and cost-effective, large-scale production of $\mathrm{ZnO} \mathrm{NRs}$ or ultrathin secondary NWs thanks to its low synthesis temperature at atmospheric pressure, and to modest requirement on equipment. A simple preparation that involves sputter depositing an 8 to $10 \mathrm{~nm}$ thin layer of $\mathrm{Zn}$ that self-oxidizes into $\mathrm{ZnO}$ is fully adequate for initiating the growth of $\mathrm{ZnO} N R s . \mathrm{Zn}$ is an excellent substitute to $\mathrm{ZnO}$ as target materials for the deposition of a seed layer. To obtain dense and vertical $\mathrm{ZnO} N R s$, a high concentration of solution are preferred. It is found in this work that in an equimolar of $\mathrm{Zn}\left(\mathrm{NO}_{3}\right)_{2}$ and HMTA with concentration of 0.0025 to $0.005 \mathrm{M}$ at atmospheric pressure, nucleation of dens NRs occurs only at temperatures above $50^{\circ} \mathrm{C}$. Small $\mathrm{ZnO}$ grains in the seed layer alone do not determine the diameter of the synthesized $\mathrm{ZnO}$ NRs, but the available amount of precursor in the solution also plays a very important role. Concentrations below $0.0025 \mathrm{M}$ will give very sparse, hardly useful nucleation of $\mathrm{ZnO}$ NRs. To obtain ultrathin secondary $\mathrm{ZnO} \mathrm{NWs}$, the concentration, temperature, and growth time of the solution have to reach a threshold value. The experiments showed that ultrathin and long secondary $\mathrm{ZnO} \mathrm{NWs}$ with average diameters of less than $20 \mathrm{~nm}$ can be synthesized on top of $\mathrm{ZnO} N R s$ in a solution with concentration of $0.005 \mathrm{M}$ at $90^{\circ} \mathrm{C}$ for $16 \mathrm{~h}$ or longer. A mechanism for the growth of ultrathin secondary $\mathrm{ZnO} \mathrm{NWs}$, including three steps, being (i) nucleation and growth of NRs, (ii) sharpening the tips of NRs and nucleation of secondary seeds, and (iii) the growth of ultrathin secondary $\mathrm{ZnO} N W s$, is proposed. The determination of the threshold value of precursor concentration, $\mathrm{C}_{\mathrm{c}}$, at a given temperature and pressure for nucleation of ultrathin secondary NWs is relevant, and is within the scope of our future work.

\section{ACKNOWLEDGEMENT}

The authors thank the Chinese Scholarship Council for supporting Mingzhi Jiao, and the Vietnam National Foundation for Science and Technology Development for funding the project 103.02-2014.06.

\section{COMPETING INTERESTS}

Authors have declared that no competing interests exist.

\section{REFERENCES}

1. Bøjesen ED, Jensen $K M \varnothing$, Tyrsted C, Lock N, Christensen M, Iversen BB. In situ powder diffraction study of the hydrothermal synthesis of $\mathrm{ZnO}$ nanoparticles. Cryst. Growth Des. 2014; 14:2803-2810.

2. Chen LY, Yin YT. Facile continuous flow injection process for high quality long $\mathrm{ZnO}$ 
nanowire arrays synthesis. Cryst. Growth Des. 2012;12:1055-1059.

3. Rai $P$, Khan $R$, Ahmad R, Hahn YB, Lee $\mathrm{IH}, \mathrm{Yu}$ YT. Gas sensing properties of single crystalline $\mathrm{ZnO}$ nanowires grown by thermal evaporation technique. Current Applied Physics. 2013;13:1769-1773.

4. Lupan O, Chow L, Pauporté T, Ono LK, Roldan Cuenya B and Chai G. Highly sensitive and selective hydrogen singlenanowire nanosensor. Sensors Actuators B: Chem. 2012;173:772-780;

5. Abdi Y, Jebreiil Khadem SM, Afzali P. Resonantly excited $\mathrm{ZnO}$ nanowires for fabrication of high sensitivity gas sensor. Current Applied Physics. 2014;14: 227-231.

6. Xu C, Tamaki J, Miura N, Yamazoe N. Grain size effects on gas sensitivity of porous $\mathrm{SnO}_{2}$-based elements. Sensors Actuators B: Chem. 1991;3:147-155.

7. Hieu NV, Loan LTN, Khoang ND, Minh NT, Viet DT, Minh DC, Trung T, Chien ND. A facile thermal evaporation route for largearea synthesis of tin oxide nanowires: Characterizations and their use for liquid petroleum gas sensor. Current Applied Physics. 2010;10:636-641.

8. Schmidt-Mende L, MacManus-Driscoll JL. $\mathrm{ZnO}$ - nanostructures, defects and devices. Materials Today. 2007;10:40-48.

9. Huang $\mathrm{MH}$, Wu Y, Feick $\mathrm{H}$, Tran $\mathrm{N}$, Weber $E$, Yang $P$. Catalytic growth of zinc oxide nanowires by Vapor Transport. Adv. Mater. 2001;13:113-116.

10. Yang $\mathrm{P}$, Yan H, Mao S, Russo R, Johnson J, Saykally R, et al. Controlled Growth of $\mathrm{ZnO}$ Nanowires and their optical properties. Adv. Funct. Mater. 2002;12: 323-331.

11. Wang X, Summers CJ, Wang ZL. Largescale hexagonal-patterned growth of aligned $\mathrm{ZnO}$ nanorods for nanooptoelectronics and nanosensor arrays. Nano Lett. 2004;4:423-426.

12. Nguyen N, Quy CT, Hoa ND, Lam NT, Van Duy N, Van Quang V, et al. Controllable growth of $\mathrm{ZnO}$ nanowires grown on discrete islands of $\mathrm{Au}$ catalyst for realization of planar-type micro gas sensors. Sensors Actuators B: Chem. 2014;193:888-894.

13. Strano V, Urso RG, Scuderi M, Iwu KO, Simone $F$, Ciliberto $E$, et al. Double role of HMTA in $\mathrm{ZnO}$ nanorods grown by chemical bath deposition. J. Phys. Chem. C. 2014; 118:28189-28195.
14. Li Q, Kumar V, Li Y, Zhang H, Marks TJ, Chang $\mathrm{RPH}$. Fabrication of $\mathrm{ZnO}$ nanorods and nanotubes in aqueous solutions. Chem. Mater. 2005;17:1001-1006.

15. Vayssieres L. Growth of arrayed nanorods and nanowires of $\mathrm{ZnO}$ from aqueous Solutions. Adv. Mater. 2003;15:464-466.

16. Hong HS, Chung GS. Controllable growth of oriented $\mathrm{ZnO}$ nanorods using Ga-doped seed layers and surface acoustic wave humidity sensor. Sensors and Actuators B: Chemical. 2014;195:446-451.

17. Greene LE, Law M, Tan DH, Montano M, Goldberger J, Somorjai G, et al. General route to vertical $\mathrm{ZnO}$ nanowire arrays using textured $\mathrm{ZnO}$ seeds. Nano Lett. 2005;5:1231-1236.

18. Sun Y, Fuge GM, Fox NA, Riley DJ, Ashfold MNR. Synthesis of aligned arrays of ultrathin $\mathrm{ZnO}$ nanotubes on a si wafer coated with a thin $\mathrm{ZnO}$ film. Adv. Mater. 2005;17:2477-2481.

19. Cakir AC, Erten-Ela S. Comparison between synthesis techniques to obtain $\mathrm{ZnO}$ nanorods and its effect on dye sensitized solar cells. Advanced Powder Technology. 2012;23:655-660.

20. Breedon M, Rahmani MB, Keshmiri SH, Wlodarski W, Kalantar-Zadeh K. Aqueous synthesis of interconnected $\mathrm{ZnO}$ nanowires using spray pyrolysis deposited seed layers. Materials Letters. 2010;61: 291-294.

21. Wang C, Shen E, Wang E, Gao L, Kang Z, Tian C, Lan Y, Zhang C. Controllable synthesis of $\mathrm{ZnO}$ nanocrystals via a surfactant-assisted alcohol thermal process at a low temperature. Materials Letters. 2005;23:2867-2871.

22. Consonni V, Sarigiannidou E, Appert E, Bocheux A, Guillemin S, Donatini $F$, et al. Selective area growth of well-ordered $\mathrm{ZnO}$ nanowire arrays with controllable polarity. ACS. Nano. 2014;8:4761-4770.

23. Ko W, Jung $N$, Lee $M$, Yun $M$, Jeon $S$. Electronic nose based on multipatterns of $\mathrm{ZnO}$ nanorods on a quartz resonator with remote electrodes. ACS. Nano. 2013;7: 6685-6690.

24. Wang X, Xie S, Liu J, Kucheyev SO, Wang YM. Focused-ion-beam assisted growth, patterning and narrowing the size distributions of $\mathrm{ZnO}$ nanowires for variable optical properties and enhanced nonmechanical energy conversion. Chem. Mater. 2013;25:2819-2827. 
25. Sun Y, Riley DJ, Ashfold MNR. Mechanism of $\mathrm{ZnO}$ nanotube growth by hydrothermal methods on $\mathrm{ZnO}$ film-coated Si substrates. J. Phys. Chem. B. 2006;110:15186-15192.
26. Morin SA, Bierman MJ, Tong J, Jin S. Mechanism and kinetics of spontaneous nanotube growth driven by screw dislocations. Science. 2010;328:476-480.

(c) 2016 Jiao et al.; This is an Open Access article distributed under the terms of the Creative Commons Attribution License (http://creativecommons.org/licenses/by/4.0), which permits unrestricted use, distribution, and reproduction in any medium, provided the original work is properly cited.

Peer-review history:

The peer review history for this paper can be accessed here: http://sciencedomain.org/review-history/12229 